\title{
Flexible Organizational Structure for Learning Organization: The Case of Indonesia Open University (Universitas Terbuka)
}

\author{
Agus Joko Purwanto \\ Department of Administrative Science, Faculty of Social and Political Science, Universitas Terbuka (Indonesia Open \\ University) \\ Jakarta 15418, Indonesia \\ ajoko@ut.ac.id
}

\begin{abstract}
Indonesia Open University (Universitas Terbuka/UT) was founded in 1984. The aim of founding UT is to provide higher education through distance learning. UT operates throughout Indonesia and abroad. With student population reaching 313 thousands, UT is a complex organization which requires effective management. Effective management should be supported by a flexible organizational structure. According to Marquardt and Reynolds (1994), to transform an organization into a learning organization (LO), an organization needs to pay attention to 11 components such as appropriate organizational structures, the culture of organizational learning, empowerment, environment, the creation and transfer of knowledge, learning technology, quality, strategy, climate learning support, teamwork and networking, and vision. This paper describes the design of the UT organization structure. Meta-analysis of three studies at UT in 2013 and 2014 was applied to this research. According to the Statute, UT organizational structure is a combination of a functional organizational structure and geographical divisions. But in reality, UT's management allows the emergence of new components within its organizational structure according to their individual needs, and therefore UT has created a lot of teams to support its operation and also established a networking with external stakeholders. In 1998, UT formulated its vision and mission but the real transformation of UT has started since 2001 by formulating objectives and targets and then followed by creating a quality assurance system, changes in the organizational structure and intensive use of information systems for learning and management. The transformation happened through team works. Organizational culture develops base on the value of the total quality management and good corporate governance. Departments are given authority to propose and use the budget flexibility in communication and the growth of informal groups that led to sharing knowledge and values among employees.
\end{abstract}

Keywords: organizational design, organizational structure, decentralization, flexibility, communication, informal organization

\section{INTRODUCTION}

Universitas Terbuka (UT/The Indonesia Open University) is a university with a long-distance mode which was founded in 1984. The purpose of UT establishment is to provide higher education to adults and high school graduates through distance learning which provides flexible learning system. UT operates throughout Indonesia and abroad and has 38 regional offices located in every province, and one regional office located in UT's head office to serve the students abroad.

In the first half of 2015, the number of UT registration students has reached 313.059 people who live in every province and overseas. The majority of UT students are adults, working as teachers, private employees and civil/military/police, and self-employed. UT provides online as well as face to face tutorial with 66.329 and 207.027 participants for each, while the examination is conducted in 1,019 locations across Indonesia and overseas. Online examination is conducted for 728 subjects matter. Those data show that UT is an organization that has a high complexity [1].

Managing a high complex organization requires a flexible organization with effective management system based on appropriate organizational culture and structure. According UT Statute, UT organizational structure is a combination of a functional structure and geographical divisions. But in reality, UT management allows the emergence of new components within its organizational structure to fulfill specific needs. UT also forms many teams and networking with external stakeholders. UT work culture is directed to be a LO, adaptive, flexible, 
democratic, visionary, quality-based, and competitive. UT also establishes the values of total quality management (TQM) and corporate and good governance (CGG) to develop UT corporate culture [2]. It shows the policy of UT development which is guided into an adaptive organization in a rapid environmental change.

In 2005, the International Council for Distance Education (ICDE) considered UT to become a "learning organization (LO)" (ICDE, 2005). In the 2010, ICDE audit results stated that the UT has a world-class system [3] with indicators such as: good strategic planning; self instructional and multimedia and digital teaching materials; multimedia materials production,; industrial standard for distribution and the storage of teaching materials; open, transparent, and a competitive recruitment of employee; human resource development in line with the policy of human resource development, and has high commitment to continuously maintain and improve the quality, and openness in developing new ideas and innovation [4].

Previous research found that the factors contributing to knowledge creation at UT is the high technical ability of team members, team members experience and knowledge, extensive autonomy within work teams, fault tolerance, institutional support, and sufficient infrastructure. The limiting factors, on the other hand, are the coordination among team members, the lack of allocation of time, lack of vision on team members [5]. Another study found that UT is an effective learning organization, which is indicated by effective information system and a strong organizational culture [6]. By becoming LO, UT has been able to encourage their employees to develop high quality of services continually. The fundamental questions that can be asked is how to design the organization so that UT able to transform into a LO?

The aim of this paper is to discuss UT organizational design and its organizational design models. The analytical method used was a meta-analysis. The source of data was three studies by the author conducted at UT in 2013 and 2014. These studies were the study of variables that affect the LO at UT, factors influencing the knowledge creation at UT, and the effectiveness of the regional offices organizational structure.

\section{THEORETICAL FRAMEWORKS.}

There are at least three meanings of a LO. Senge [7] defines LO as a place. Garvin [8] defined LO as the ability of an organization. Meanwhile, Schermerhorn, et al. defined LO as a process within the organization. The ultimate goal of an organization transformation into a LO is successfully adapting to changing circumstances [9]

When organization wants to transform into LO, organization needs to set its goals and strategies of transformation. Jones and George [10] defined LO as "an organization that designs and constructs it purposefully structure, culture, and strategy so as to enhance and maximize the potential for organizational learning to take place". In line with Jones, Espejo, et al. [11], explained that the organizational structure is an important component in LO. Thus the organizational structure is an important part of the LO. In order to facilitate the growth of LO, the organizational structure should be designed effectively.

Organizational design is defined as the process by which managers select and manage aspects of structure and culture [12]. Stanford [13] stated that the organization design is how people and work are organized to carry out an organization's strategy and achieve its aims. Daft [14] used the term organizing to refer to the organization design. According to Daft, organizing is the deployment of organizational resources to achieve strategic goals. The core of the design of the organization is how to organize the organization's resources to achieve the goal.

As previously described, one important component of organizational design is the organizational structure. According to Colquitt, et al. [15], organizational design is the process of creating, selecting, or changing the structure of an organization. Jones and George [10] also defined organizational design as the process by which managers makes specific organizing choices that result in a particular kind of organizational structure". Colquitt and Jones said that organization design choose the right organizational structure.

According to Jones [12], designing an organization is a process of balancing; (1) differentiation with integration, (2) centralization with decentralization, (3) standardization with mutual adjustment. There are several variables that affect to design the organization such as environment, organization size, technology, organization strategy, and worldwide operations [16].

As stated by Colquitt, Jones and George, designing organization means designing the organizational structure. The structure is an important element of an organizational learning and empowerment; therefore, the structure must be responsive to environmental changes. Responsive organization should be designed towards the direction that organization based on not on hierarchy but on flexible, collaborative networks [17].

As a part of organizational learning and knowledge creation, a design for a new organization will produce an organization which: (1) tends to be flatter, (2) is a constant dynamic, (3) supports the empowerment of people, (4) 
emphasizes the importance of competencies, (5) recognizes the intellect and knowledge [18]. Controls that rely on informal culture and communication. In the language of Peters and Waterman, try install a simple and workable structure, people will figure out the rest [19].

The organizational structure is a chart that describes (1) a description of the structure of tasks and jobs, (2) the forms of coordination, (3) communication, (3) reporting relationships, (4) the flow of work, and (5) the use of the authority to regulate the activities of the organization in order to achieve organizational goals. According to Minztberg, a model of organizational structure that is commonly used is functional, divisional (product, geographic, market, process, and customer), matrix structure, and network structure [20].

Organizational design which includes the design of structure and culture when it is integrated with total quality management (TQM) will accelerate the process of transforming the organization into LO. TQM is abridging transformation from a regular organization to LO. Lam, Poon, and Chin [21] reported that TQM culture (TC) is the important link between organizational learning (OL) and TQM and its functions as an enabler for LO. Meanwhile, Konidari and Abernot [22] discovered that the school as an LO can be achieved by combining TQM and organizational learning's principles, by empowering employees, by creating professional communities, and by proceeding in a methodological re-evaluation.

Accuracy in combining the structure and culture will produce organizational designs that provide flexibility for employees. This flexibility will have a significant impact on employee motivation and ability to learn through a process of questioning, experimentation, and creating new knowledge.

\section{FINDINGS AND DISCUSSION}

Universitas Terbuka's organizational structure as stated in the Decree of the Minister of Education and Culture No. 23/ 2007 on the Statute of Universitas Terbuka. According to the Statute, UT's organizational structure is a combination of functional structure and geographical divisions. In fact, this is not sufficient when it is used by departments to execute the workload. Considering various departments' needs to manage their workload, for certain circumstances, UT established several working teams. The phenomenon indicates that the organizational structure can be assumed as adhocracy or a matrix structure with complex coordination mechanisms. The flexibility of management is to adjust the organizational structure as needed and clearly shows that the authority should be granted to create additional structure of the organization as stated by Jones, Stanford, Daft, and Colquitt.
As an open and distance learning university with a huge number of students all over the country, UT needs strategic partners with other parties or individuals to provide academic services. These include services for online and face to face tutorials, examinations, teaching materials development, and study group management. To fulfill these services, UT needs to maintain their networks continuously then drives UT to apply network structure in its organization.

Another type of organizational structure implemented in UT's organization is that it is based on work process. For example, UT has two bureaus which are responsible to manage academic administration and financial affairs. UT also has five centers to support its operation to produce and distribute their teaching materials, managing learning support, maintaining data, maintaining application, maintaining information communication, and maintaining information technology, providing services in learning resources, managing and developing human capital and assuring quality. This kind of differentiation provides opportunity for UT to adopt the total quality management (TQM) since TQM can bridge UT to transform into LO. The implementation of TQM has helped UT develop its organizational culture so that it becomes easier to transform into LO as identified by Purwanto and Marisa [25]. UT actual organizational structure is described as follows.

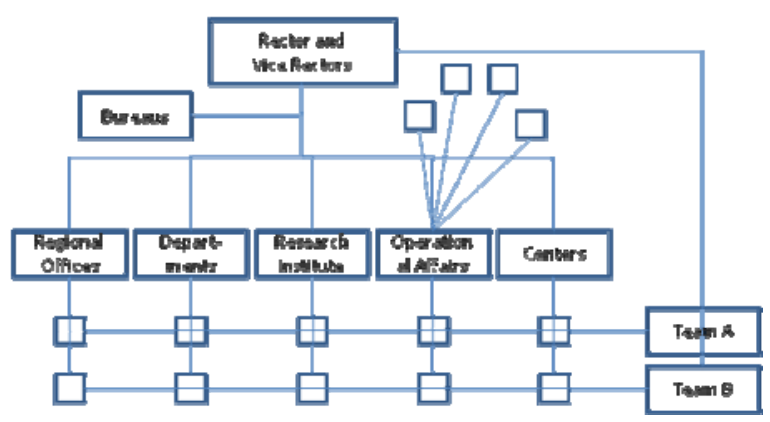

Fig. 1. UT Actual Organizational Structure

\section{KNOWLEDGE CREATION IN UNIVERSITAS TERBUKA}

A flexible organizational structure provides: (a) multidirection flow of information. (b) an organizational structure which can facilitate the process of knowledge creation. (3) a full authority of teamwork and tolerance for errors. These are considered as major factors contribute to the success of knowledge creation process as identified by Purwanto and Marisa [5].

The findings indicate: firstly, better coordination in the organization. Coordination is done using various channels 
such as meetings, memos, and letters as well as using media (blackberry messenger, SMS, email, website, telephone, video conference). Secondly, formal and informal communication are both effective. Thirdly, work reports can be submitted directly or using the media. Finally, employees have sufficient authority to make decisions. The findings showed that there was compatibility between UT organizational structure with the concept of organizational structure proposed by Jones and George, Daft, and Robbins and Judge.

In a study on the effectiveness of organizational structure of ROs, it was found that UT management also gives authority to the ROs to make adjustments of its organizational structure suitable with local conditions.

ROs organization structure according UT Statute:

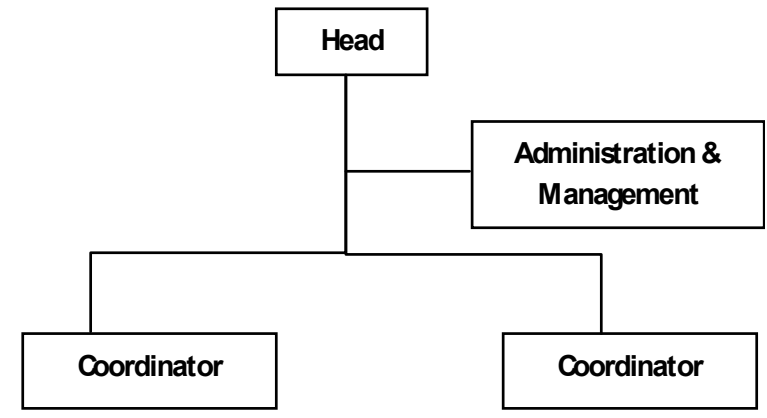

Fig.2 The Original Organizational Structure According to UT Statute

Similar to head office organizational structure, the organizational structure of Surakarta Regional Office also has been adjusted to suite their own needs. Surakarta regional office added a new unit to provide services for students and assigned nine employees responsible for nine districts. Fig. 3 shows the adjusted organizational structure of Surakarta Regional Office.

Data collected in Surakarta regional office showed (a) a clear job description in the Statute and RO Guidelines; (b) an effective span of control; (c) good coordination in managing routine and incidental work through meetings, developing work teams, and assigning staff to responsible for the certain districts; (d) effective communication. Downward as well as upward communication was used either sideways or diagonally and informal one. (e) flexible policy to regional office to modify their own internal management. Those factors contribute significantly to the increase of the organizational effectiveness [27]

Those show that the structure and organizational culture take an important role in the transformation of the UT organization into LO. The flexibility of the organizational structure, decentralized decision making, and intensive communication is driving factors in transforming UT into LO. Managers need to design the organization to facilitate ongoing sharing knowledge and value.

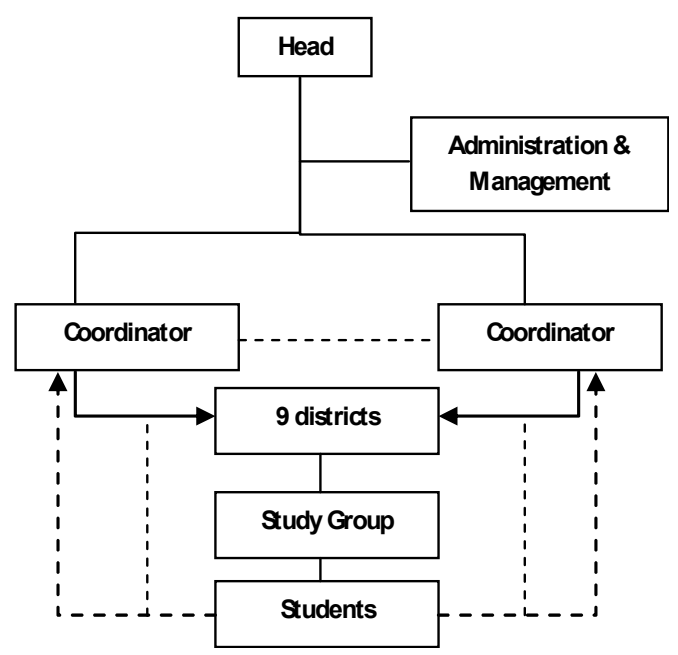

Fig. 3 Surakarta Organization Structure

\section{CONCLUSIONS}

Legally, UT organizational structure is a combination of a functional organizational structure and geographical divisions, but practically, matrix organizational structure is implemented, and to some extent, turned into a network structure. UT also adopts the values of TQM and corporate and good governance. By ICDE, UT has been declared as LO. UT as a LO is as effective as the organizational structure and culture. It provides support for sharing knowledge and value. Supported by good information system, it can overcome barriers in communication.

TQM strategy adopted by UT leads to easier implementation of this LO. In UT, TQM is able to be a bridge for UT transformed into LO. TQM helps to set up a UT organization's culture so that it becomes easier for UT transformed into LO. Another factor to be taken into account in the transformation is the role of informal communication and IT implementation. With good IT facilities, informal communication will be capable to penetrate the bulkhead hierarchy and used real time so that sharing knowledge and value can take place effectively.

\section{Reference}

[1] Universitas Terbuka, Report of Service Performance and Finance of Universitas Terbuka Semester I Year of 2015, Document Unpublished, 2015.

[2] Memorandum End of Tenure of Rector of Universitas Terbuka 2005-2009 (Jakarta, Universitas Terbuka, 2009), Unpublished. 
[3] International Council for Distance Education (ICDE) Institutional Quality Audit, Universitas Terbuka, 6-10 Juni 2005. Unpublished.

[4] A.J. Purwanto, "The Effect of Information systems, organizational structure, organizational culture, and human resource development to learning organization", Dissertation, 2014. The Open University, Unpublished.

[5] A.J. Purwanto, and Marissa, "Knowledge creation process in developing academic products and service system in Universitas Terbuka (Indonesian Open University)", paper presented in Asia Association of Open University Conference at Hong Kong, 2014, pp. 28-31.

[6] A.J. Purwanto, and Marissa, "The Effect of Information System, Organizational Structure, Human Resource Development, and Organizational Cultures to Universitas Terbuka's Learning Organization", paper presented on International Seminar and Conference of Learning Organization (ISCLO), Jakarta, November 2014.

[7] P.M. Senge, The Fifth Discipline: The Art and Practice of the Learning Organization, New York: Currency Doubleday, 2006.

[8] D.A Garvin, Learning in Action: A Guide to Putting The Learning Organization to Work. Boston: Harvard Business Review Press, 2000.

[9] J. R. Schermerhorn, Jr., G.H. James, R. N. Osborn, and M. UhlBien, Organizational Behavior (11th ed.), New Jersey: John Wiley and Sons, 2011, ISBN 978-0470294413.

[10] G.R. Jones, and J. M. George, (5th ed.) Contemporary Management, Boston: McGraw-Hill Irwin, 2008, ISBN 9780077534950 .

[11] R. W. S. Espejo, M. Schwaninger, \& U. Bilello, Organizational Transformation and Learning; A Cybernetic Approach to Management, West Sussex: John Wiley and Sons, 1996, ISBN 978-0471961826

[12] J. Gareth, Organizational Theory, Design, and Change (6th ed.), Boston, Prentice Hall, 2010, ISBN 978-0136087311.

[13] N. Stanford, Guide to Organization Design: Creating High Performing and Adaptable Enterprises (2nd ed.), Profile Books, London, 2015, ISBN 978-1610395397.

[14] R.L. Daft, Organization: Theory and Design (6thed.). Cincinnati: South Western College Publishing, 1998, ISBN 978-0324598896.

[15] J.A. Colquitt, J. A. Lepine, and M.J Wesson, Organizational Behavior: Improving Performance and Commitment in the Workplace. New York: McGraw-Hill Irwine, 2011, ISBN 9780077862565 .

[16] T.G. Cummings, and C.G. Worley, Organization Development and Change (8th ed). Ohio: South-Western, 2005, ISBN 9780324260601

[17] D. Limerick, and B. Cunnington, Managing The New Organization: A Blueprint for Network and Strategic Alliances, West Chatswood, New South Wales: Jossey-Bass, 1993, ISBN 978-1555425814.

[18] I.Nonaka, dan T. Hirotaka, The Knowledge Creating Company: How Japanese Companies Create the Dynamics of Innovation. New York: Oxford University Press, 1995, ISBN 9780195092691.

[19] T. Peters, and R. Waterman Jr, In Search of Excellence: Lesson from American's Best-Run Companies, London: Profile Books Ltd, 2004, ISBN 978-1861977168.

[20] H. Mintzberg, Structure in Fives; Designing Effectives Organizations, New Jersey: Prentice Hall, Inc., 1983, ISBN 9780138554798.

[21] M.Y. Lam, G.K.K. Poon, and K.S. Chin, "An organizational learning model for vocational education in the context of TQM culture", The International Journal of Quality \& Reliability Management, Vol. 25, Issue.3, 2008, pp. 238-255.

[22] V. Konidari, dan Y. Abernot, "From TQM to learning organisation: Another way for quality management in educational institutions", International Journal of Quality \& Reliability Management, Vol. 23 Iss: 1, 2006, pp.8 - 26.

[23] A.J. Purwanto, "Informational technology as the backbone of effectiveness of regional offices of the Open University organizational structure", Paper presented on 29th Annual Conference of th Asian Association of Open University, 30 November-2 December 2015 at Kuala Lumpur. 